\title{
Evaluation of Isfahan Inhabitant Attitude About Brucellosis and Common its Herbal Treatment
}

\author{
Mohsen Ghomashlooyan ${ }^{1}$; Mehdi Azami ${ }^{2}$; Mohammad Ali Mohaghegh ${ }^{1}$; Mahboobeh \\ Hadipour $^{1}$;Somayeh Jahani ${ }^{3}$;Seyed Hossein Hejazi ${ }^{1,2}$; Fereshteh Moradzadeh ${ }^{4}$; Ahmadreza \\ Barahimi $^{5,}$ \\ ${ }^{1}$ Department of Parasitology and Mycology, School of Medicine, Isfahan University of Medical Sciences, Isfahan, IR Iran \\ ${ }^{2}$ Skin Diseases and Leishmania Research Center, School of Medicine, Isfahan University of Medical Sciences, Isfahan, IR Iran \\ 3 Infectious Diseases and Tropical Medicine Research Center, Zahedan University of Medical Sciences, Zahedan, IR Iran \\ ${ }_{5}^{4}$ Department of Cellular and Molecullar Biology, Nour Danesh Institute of Higher Education, Isfahan, IR Iran \\ 5 Department of Medical Mycology, School of Medicine, Tarbiat Modares University, Tehran, IR Iran \\ ${ }^{*}$ Corresponding author: Ahmadreza Barahimi, Department of Medical Mycology, School of Medicine, Tarbiat Modares University, Tehran, IR Iran. Tel: +98-9132108829, \\ E-mail: ahmad_laboratorysciences@ymail.com
}

Received: November 1, 2014; Revised: March 14, 2015; Accepted: March 16, 2015

\begin{abstract}
Background: Brucellosis, also called Malta fever, is a highly contagious zoonosis caused by ingestion of unpasteurized milk or undercooked meat from infected animals, or close contact with their secretions. Brucella species are small, Gram-negative, non-motile, non-spore-forming, rod-shaped (coccobacilli) bacteria.

Objectives: The aim of this study is to perform an evaluation of Isfahan inhabitant attitude about brucellosis and its common herbal treatment.

Patients and Methods: This evaluation was a simple random sample study, which was carried out on 162 people in the city of Isfahan, Iran, by means of questionnaires. The data was analyzed using SPSS for Windows (Version 21.0).

Results: Of 162 people that were interviewed, 90 (55.6\%) patients were male and the other were female. Of these, 74 (45.7\%) patients were single and $88(54.3 \%)$ were married. Forty-three (26.5\%) participants lived in the city. The average age of participants was $11.51 \pm 29.11$ years. There is no significant relationship between age, gender, education level, residence, and people familiar with the disease brucellosis, herbal treatment for brucellosis $(\mathrm{P}>0.05)$.

Conclusions: Our data suggest that the demographic and socioeconomic characteristics of people in Isfahan, Iran, show no relationship with the attitude of individuals regarding brucellosis and towards common herbal treatments for the disease.
\end{abstract}

Keywords: Brucellosis; Treatment; Herbal Preparations; Demographic Factors

\section{Background}

Therapeutic effects and uses of medicinal plants are evident to everyone. The return towards nature and reuse of natural plant-based medicines occur in a the present context, in which the modern man, by strengthening and promoting the use of more chemical compounds, had faced itself to adverse side effects of these drugs (1). Although the use of medicinal plants is limited by the development of the chemical industry, however, the prospect of using these plants is increasing (2). Scientific research has proven efficacy and safety of a number of methods of alternative medicine, such as medicinal plants, in the treatment of several diseases (3-5). Unfortunately, accurate statistics on the prevalence of herbal and chemical drugs that cause side effects because of the uninformed and arbitrary use, are not available in Iran (6). The lack of attention towards the development of medicinal plants had high costs for our country. Only 1 - 3\% of the country's annual consumption of drugs is represented by medicinal plants and a cost of 500 million dollars, from the public funds, to provide the drugs can be evidence in this regard (7). Roughly $80 \%$ of drugs that are supplied in several countries have a plant-based composition and the use of medicinal plants has greatly increased in developed countries, to such a degree that, presently, $90 \%$ of people in these countries use herbal medicines ( 8 , 9 ). The role of medicinal plants in peoples beliefs and culture and the increasing global tendency to use natural compounds, are the strengths and opportunities facing the field of medicinal plants (10).

Brucellosis is a zoonotic disease in humans, which can also infect a range of animals (11). In humans, brucellosis is a systemic disease that can affect various organs and cause nonspecific symptoms (12). From six known spe- 
cies, only four species of Brucella-inducing disease to humans and capable of causing infection (13).

Considering the importance medicinal plants and the need for public awareness of the benefits of this class of plants, as natural medicines that have fewer adverse side effects than chemical drugs, and given the increased prosperity of agriculture and animal husbandry, in Isfahan province, Iran, therefore increasing the incidence of zoonotic diseases, especially brucellosis, we are faced with the issue of the understanding of people's attitudes towards herbal medications in the treatment of brucellosis, which can have a constructive role in science.

\section{Objectives}

The aim of this study is the evaluation of Isfahan inhabitants' attitude toward brucellosis and common herbal treatment for the disease.

\section{Patients and Methods}

\subsection{Study Area}

Isfahan is one of the largest cities in Iran. The Isfahan province covers an area of approximately 107,027 km² and is situated in the center of Iran. It has a moderate and dry climate and its temperature ranges between $40.6^{\circ} \mathrm{C}$, in hot summers, and $10.6^{\circ} \mathrm{C}$, on a cold day in the winter season. The average annual temperature has been recorded as $16.7^{\circ} \mathrm{C}$ and the annual rainfall, on an average, has been reported as $116.9 \mathrm{~mm}$.

\subsection{Sample Selection}

This study included 162 native inhabitants of Isfahan province. The study period was from June 2009 to April 2010.

The survey was carried out among a sample of representative telephone households, by using random-digit dialing to select households and a random selection method to select one respondent age 18 or older, for interview, in each sample household. Informed consent was obtained from all respondents before they began the interview. The average administration time was 30 minutes.

\subsection{Evaluation of Questionnaires}

The interview was described to respondents as a survey about Isfahan native inhabitant attitude about herbal medicine, especially against brucellosis. No mention was made of complementary and alternative therapies, in characterizing the study. The first substantive questions were about familiarity with the disease. The next questions asked about the degree of familiarity of the respondent with common herbal treatment for brucellosis. The categories "Which kind of drug is better, herbal or chemical" and "Which physician is better, Traditional physician or Non-traditional physician" were included in this checklist.

Users of each herbal and chemical therapy were then asked their age, at first use, then sex, marriage, educational level, habitat and, finally, ways to learn about herbal medicine.

\subsection{Statistical Analysis}

The questionnaire was designed and completed a pilot study for 30 patients. Validity and reliability of the questionnaires were confirmed by the study experts and the criterion Cronbach alpha level was 0.89. In this study, descriptive statistics (mean, standard deviation), $\chi^{2}$ tests, and Pearson correlation were performed to determine whether there were statistically significant associations between people knowledge and the use of herbal medicine. Finally, the data were analyzed using SPSS for Windows (Version 21.0) (SPSS Inc., Chicago, IL, USA).

\section{Results}

A total of 162 people were interviewed, of which 90 (55.6\%) patients were male and the other were female. Of these, 74 (45.6\%) patients were single and 88 (54.3\%) were married, while 43 (26.5\%) of participants lived in the city. Average age of participants was $11.51 \pm 29.11$ years. Most participants, 73 (45.1\%), made use of books as a good way to access information about the disease, while the next means of information come as follows: internet 46 (28.4\%), radio 17 (10.5\%), TV14 (8.6\%), friends and acquaintances 12 (7.4\%).

Of the sample, $71(43.8 \%)$ had a lot of information regarding the disease and only six (3.7\%) patients were not familiar enough with the disease. Eleven (6.8\%) were familiar with herbal medicines to cure the disease and 117 (72.2\%) have been treated. Totally, 53 participants believed that herbal therapy was most effective and these patients (32.7\%) turned to traditional medicine for the treatment of brucellosis, while 9.3\% $(n=15)$ did not addressed the traditional physician.

Figure 1. Frequency of Ways That Population of Study to Learn About Herbal Medicines

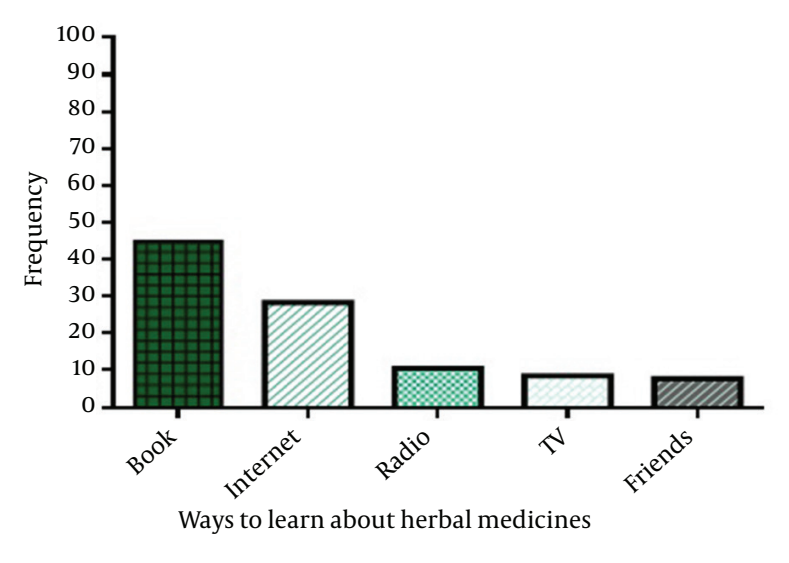


Figure 2. Prevalence of Study Population About the Brucellosis and Treatment Methods

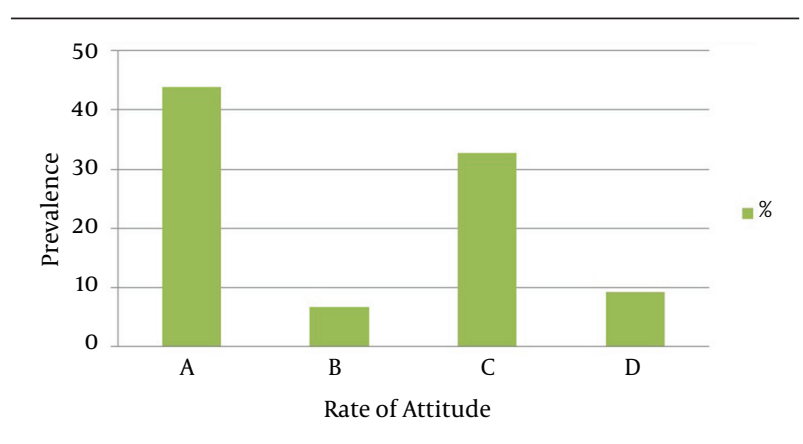

A, Familiarity with disease; B, patients' familiarity with common herbal treatment; C, type of drug; D, specialty of physician.

\section{Discussion}

Herbal medicines are supported by the experiences of multiple generations over hundreds of years of indigenous physicians practice in different parts of the world. Also, in developed countries, valuable and nutritious food has significantly attracted public attention and is marketed and consumed as a drug. Nevertheless, the demand to use herbal medicines has increased dramatically because of their efficacy, safety and low side effects, and is used for primary health care in these countries. The World Health Organization has recently defined traditional medicine (including herbal drugs) as comprising therapeutic practices that have been in existence, often for hundreds of years, before the development and spread of modern medicine, and are still in use today (14). In this study, there is no significant relationship between age, gender, education level, residence, and people familiar with brucellosis and herbal treatment for brucellosis $(\mathrm{P}>0.05)$.

However, the familiarity with brucellosis and how to access information on the disease and disponibility to go to the traditional physician and clinicians relationship were significant $(\mathrm{P}<0.001)$.

According to the results, it can be concluded that the use of various information portals lead to more familiarity with brucellosis and its causes. This study also evidenced that familiar herbs and traditional treatments are common. However, the preference of people to use herbal medicines with synthetic drugs in regions with a high incidence of brucellosis shows that people believe in the properties of herbal medicines.

This study helped facilitate the access of patients and professionals to information concerning brucellosis and the ways to promote this information. This applies to decision makers in relation to the prioritization of data requirements and helps us to achieve an optimal means of providing better understanding and easier access.

\section{Acknowledgements}

The authors are thankful to Miss Nahid Marvi Esfahani for her guidance and Isfahan inhabitants for their sincere cooperation.

\section{Authors' Contributions}

Mohsen Ghomashlooyan, Ahmadreza Barahimi, Mahboobeh Hadipour and Mehdi Azami: Conception and design, data acquisition, data analysis and interpretation, critical revision of the manuscript for scientific and factual content. Seyed Hossein Hejazi and Somayeh Jahani: Data acquisition, drafting the manuscript, statistical analysis.

\section{References}

1. Lima SC, de Arruda GO, Renovato RD, Alvarenga MR. Representations and uses of medicinal plants in elderly men. Rev Lat Am Enfermagem. 2012;20(4):778-86.

2. Simmerling C, Strockbine B, Roitberg AE. All-atom structure prediction and folding simulations of a stable protein. J Am Chem Soc. 2002;124(38):11258-9.

3. Azaizeh H, Saad B, Cooper E, Said O. Traditional Arabic and Islamic Medicine, a Re-emerging Health Aid. Evid Based Complement Alternat Med. 2010;7(4):419-24.

4. Calixto JB. Efficacy, safety, quality control, marketing and regulatory guidelines for herbal medicines (phytotherapeutic agents). Braz J Med Biol Res. 2000;33(2):179-89.

5. Hasani-Ranjbar S, Nayebi N, Larijani B, Abdollahi M. A systematic review of the efficacy and safety of herbal medicines used in the treatment of obesity. World J Gastroenterol. 2009;15(25):3073-85.

6. Najafian J, Abdar-Esfahani M, Arab-Momeni M, Akhavan-Tabib A. Safety of herbal medicine in treatment of weight loss. ARYA Atheroscler. 2014;10(1):55-8.

7. Schweitzer SO. Pharmaceutical economics and policy:: Oxford University Press; 2006.

8. Foster S. Tyler's honest herbal: a sensible guide to the use of herbs and related remedies.: Routledge; 2012.

9. Kong JM, Goh NK, Chia LS, Chia TF. Recent advances in traditional plant drugs and orchids. Acta Pharmacol Sin. 2003;24(1):7-21.

10. Abd Jalil MA, Shuid AN, Muhammad N. Role of medicinal plants and natural products on osteoporotic fracture healing. Evid Based Complement Alternat Med. 2012;2012:714512.

11. Baldi PC, Giambartolomei GH. Pathogenesis and pathobiology of zoonotic brucellosis in humans. Rev Sci Tech. 2013;32(1):117-25.

12. Ulug M, Yaman Y, Yapici F, Can-Ulug N. Clinical and laboratory features, complications and treatment outcome of brucellosis in childhood and review of the literature. Turk J Pediatr. 2011;53(4):413-24.

13. Martirosyan A, Moreno E, Gorvel JP. An evolutionary strategy for a stealthy intracellular Brucella pathogen. Immunol Rev. 2011;240(1):211-34.

14. Patwardhan B, Patwardhan A. Traditional medicine: Modern approach for affordable global health. Commission on Intellectual Property Rights IaPHC.Geneva: World Health Organisation; 2005. 